\title{
Characterization of Butadiene Styrene Rubber Composites with Halloysite Filler
}

\author{
Yuri Kornev, Hammat Valiev*, Yulya Karnet, Nikolay Semenov and Oleg \\ Yumashev \\ Institute applied mechanics RAS, Moscow, Russia
}

ISSN: 2576-8840

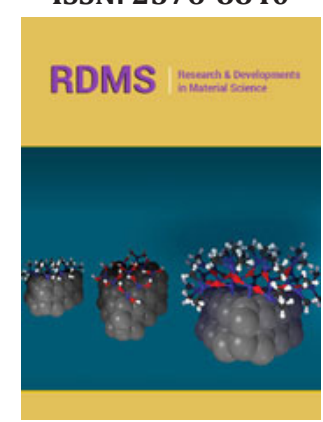

*Corresponding author: Hammat Valiev, Institute applied mechanics RAS, Moscow, Russia

Submission: 诲 June 29, 2020

Published: 酶July 07, 2020

Volume 13 - Issue 5

How to cite this article: Yuri Kornev, Hammat Valiev*, Yulya Karnet, Nikolay Semenov and Oleg Yumashev. Characterization of Butadiene Styrene Rubber Composites with Halloysite Filler. Res Dev Material Sci. 13(5). RDMS.000821. 2020. DOI: $10.31031 /$ RDMS.2020.13.000821

Copyright@ Hammat Valiev. This article is distributed under the terms of the Creative Commons Attribution 4.0 International License, which permits unrestricted use and redistribution provided that the original author and source are credited.

\section{Case Report}

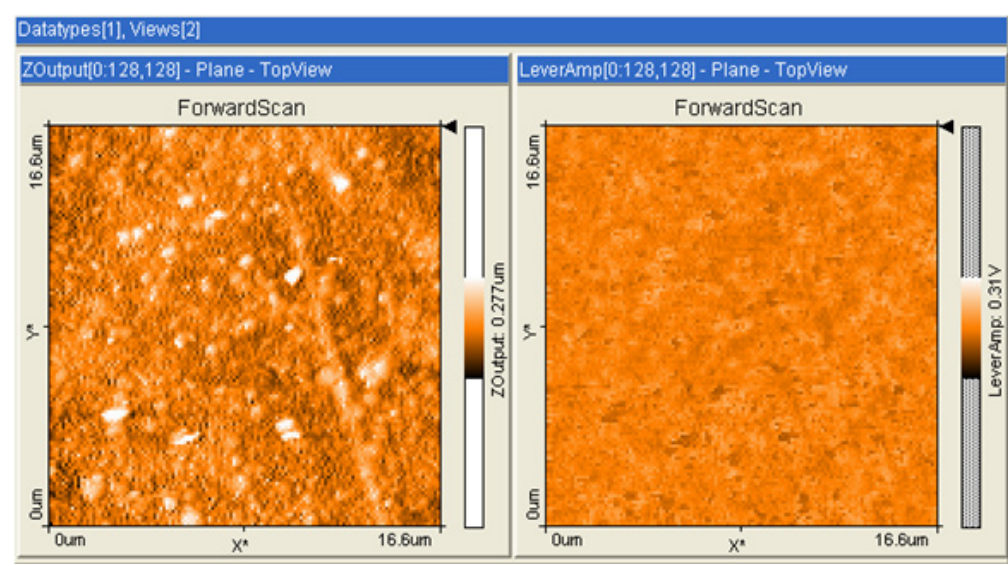

Figure 1: AFM images of rubber composites surface structure with halloysite filler.

Scan $16.6 \times 16.6 \mu \mathrm{m}^{2}$. Topography is on the left, material contrast - on the right.

The study of elastomeric composites properties with inorganic mineral fillers is of great interest both in fundamental and applied research. This paper presents experimental results of investigation the composite materials based on industrial synthetic rubber SCS30 ARC using aluminosilicate mineral halloysite as filler. Halloysite is a unique class of natural minerals.They consists of layers aluminum oxide and silicon oxide [1]. The obtained composites research surface structure by means of Atomic Force Microscopy (AFM) as well as testing of their physical and mechanical properties has been carried out. The synthesized composites were prepared with a halloysite content filling 65 mass parts per 100 mass parts of elastomer. The study of obtained samples composites was carried out with an atomic force microscope (Nanosurf, Switzerland), working in contact mode in the air at room temperature. At the same time the AFM force modulation for obtaining material contrasts of the investigated samples was used. The obtained AFM images were processed with the help of SPIP computer program (Image Metrology, Denmark). The physical and mechanical properties of composites were studied using the laboratory measurement complex Nano Test 600 (Micro Materials, England) [2,3] by the nano indentation method. The surface structure AFM images of synthesized composites are shown in Figure 1. Due to the use of the ACM force modulation mode, the dark regions of material contrast (right on the images of Figure 1) visualize halloysite agglomerates with dimensions from $100 \mathrm{~nm}$ to 1 micron in the elastomeric matrix. The halloysite aggregates and agglomerates particular features in Figure 1 are characterized by sharp anisotropy of the shape and highlighted in homogeneity of the filler particles structure. The study of these composites with the Nano Test 600 showed a large increase in strength compared to unfilled rubber, reaching values up to 5-7 MPa. After special processing and grinding particles of these fillers by means of ball planetary mill RM- 
100 (Retsch, Germany) additional strength gain of synthesized composites from 7 to $11 \mathrm{MPa}$ was achieved. An important result is also the established significant change in the relative elongation of composites at rupture, which decreased from almost $1000 \%$ to $400 \%$, when filled with halloysite after special processing. This is definitely due to the reduction in the length of the fillers tubular structure after mechanical grinding.

Thus, the use of atomic force microscopy enabled to determine the distribution patterns of aggregates and agglomerates of natural halloysite minerals in composites with butadiene styrene rubber. The morphology and micro-nanometer length range of halloysite aggregates in synthesized materials have been characterized. Correlation between reinforcement physical and mechanical properties of synthesized composite materials and distribution peculiarities of used filler in elastomeric matrix has been established.

\section{Acknowledgment}

The work was carried out on the subject of the state assignment in IPRIM RAS for the period 2019-2021. State registration number: AAAA-A19-119012290177-0.

\section{References}

1. Vinokurov VA, Stavitskaya AV, Chudakov YA (2017) Formation of metal clusters in halloysite clay nano tubes. Science and Technology of Advanced Materials 18(1): 147-151.

2. Kornev YV, Yanovskiy YG, Boiko OV (2013) The effect of carbon nano tubes on the properties of elastomeric materials filled with the mineral shungite. Int Polymer Science and Technology 40(2): 29-32.

3. Vermel VD, Titov SA, Kornev YuV (2018) Evaluation of improving mechanical characteristics of epoxy binder after dispersing carbon nano fibers using wave processes and ultrasound. Advanced materials \& technologies 4: 5-15.

For possible submissions Click below: 